\title{
Country of Origin and Brand Positioning for High-Involvement Health-Care Services: An Abstract
}

\author{
Katherine A. Meese, Thomas L. Powers, S. Robert Hernandez, \\ Andrew N. Garman, and Tricia J. Johnson
}

\begin{abstract}
Country of origin and brand positioning are important factors to consider for high-involvement services such as health-care organizations competing for international patients. These factors become more important in high-involvement service industries because consumers do not have the information needed to evaluate service quality, and the cost to the patient of poor quality is high. Therefore, consumers may rely on country of origin and brand positioning signals more heavily relative to goods or hedonic services. This paper explores the relationship between country of origin and brand positioning in the context of the highinvolvement service of health care. An analysis of brand positioning of health-care institutions using promotional materials from a large international health-care conference is presented using a sample of 170 health-care organizations located in 14 countries. The findings indicate that European and Middle Eastern health-care organizations most frequently employ foreign consumer culture positioning, while American institutions tend to use global consumer culture positioning. However, American organizations may be missing an opportunity to capitalize on the appeal of their country and cities and may not be appropriately considering their global competition in their market positioning. The findings are important for hospitals competing globally for patients seeking care abroad.
\end{abstract}

References Available Upon Request

K.A. Meese $(\triangle) \bullet$ T.L. Powers $\bullet$ S. Robert Hernandez

University of Alabama at Birmingham, Birmingham, AL, USA

e-mail: kameese@uab.edu; tpowers@uab.edu; hernande@uab.edu

A.N. Garman • T.J. Johnson

Rush University, Chicago, IL, USA

e-mail: andy_n_garman@rush.edu; tricia_j_johnson@ rush.edu 